The 65th special feature "Fluorine Chemistry and Materials for Electrochemistry"

\title{
Corrosion Inhibition for Steel Surface Using a Polyacrylic Gel Sheet Containing Ni-Al Layered Double Hydroxide Prepared by Liquid-Phase Deposition
}

\author{
Kota KAMON, ${ }^{a, \S}$ Naoki UCHIDA, ${ }^{a}$ Hideshi MAKI $\mathbb{D}^{\mathrm{D}},{ }^{\mathrm{a}, \mathrm{b}, \S \S}$ Masaki MATSUI $\mathbb{D}^{\mathrm{D}},{ }^{\mathrm{a}, \S}$ and Minoru MIZUHATA ${ }^{\mathrm{a}, \mathrm{c}, *, \S \S}$ \\ a Department of Chemical Science and Engineering, Graduate School of Engineering, Kobe University, \\ 1-1 Rokkodai-cho, Nada, Kobe 657-8501, Japan \\ b Center for Environmental Management, Kobe University, 1-1 Rokkodai-cho, Nada, Kobe 657-8501, Japan \\ c Faculty of Chemistry, Jagiellonian University, Gronostajowa 2, 30-387 Kraków, Poland \\ *Corresponding author: mizuhata@kobe-u.ac.jp
}

\section{ABSTRACT}

$\mathrm{Ni}-\mathrm{Al}$ layered double hydroxide (LDH) was prepared on a steel plate and fumed alumina by the liquid phase deposition (LPD) method with $\mathrm{NO}_{2}^{-}$inserted between the layers for rust prevention, and its corrosioninhibition effect was investigated. Anion exchange of the synthesized LDH was carried out by immersing it in aqueous $\mathrm{KOH}$ and $\mathrm{NaNO}_{2}$ solutions, separately. The composition of the obtained $\mathrm{Ni}-\mathrm{Al} \mathrm{LDH}$ is typically $\left[\mathrm{Ni}(\mathrm{II})_{0.69} \mathrm{Al}(\mathrm{III})_{0.31}(\mathrm{OH})_{2}\right] \mathrm{OH}_{0.31}$ in $\mathrm{OH}^{-}$-type LDH. Electrochemical measurements revealed the expansion of the passive area and a decrease in the corrosion current in the sample mixed with LDH, compared to the case with the pure polyacrylic gel sample. In particular, the corrosion current was reduced to less than half of the original in the samples mixed with $\mathrm{NO}_{2}^{-}-\mathrm{LDH}$. For the polyacrylic gel containing $\mathrm{LDH}$, the anodic current was suppressed at all concentrations of the aqueous $\mathrm{NaCl}$ solution, and the corrosion current was approximately

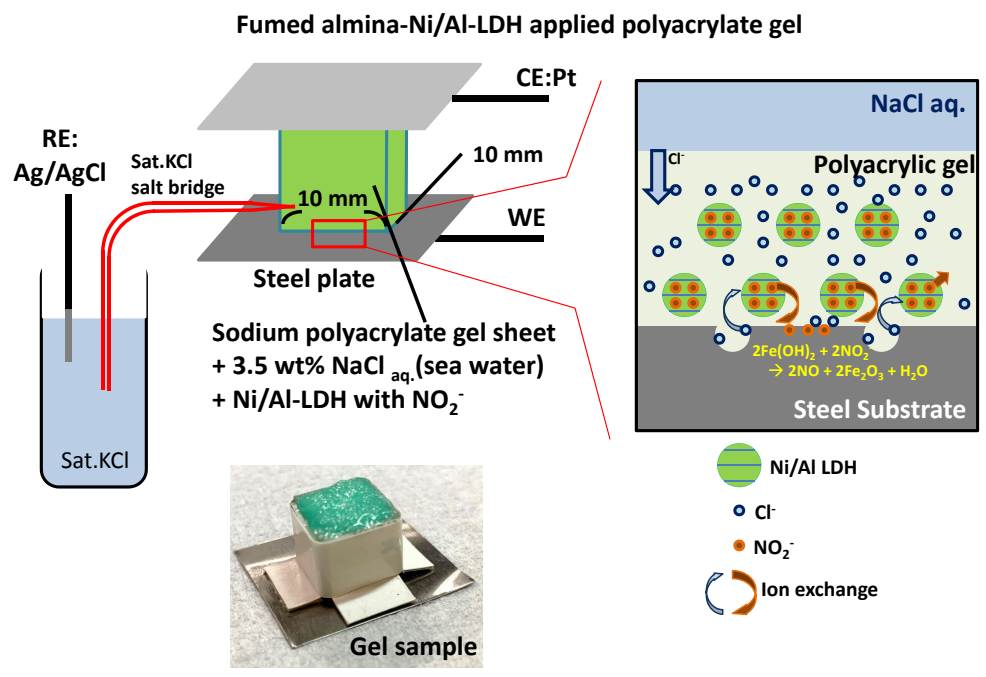
the same as the result of the polarization measurement. The corrosion-inhibiting effects due to $\mathrm{Cl}^{-}$absorption and $\mathrm{NO}_{2}{ }^{-}$release were confirmed. A good rust preventive effect was also observed in the hydrous LDH gel sheet intended to be exposed to the atmosphere where an arbitrary amount of $\mathrm{Cl}^{-}$ions is dissolved.

(C) The Author(s) 2021. Published by ECSJ. This is an open access article distributed under the terms of the Creative Commons Attribution 4.0 License (CC BY, http://creativecommons.org/licenses/by/4.0/), which permits unrestricted reuse of the work in any medium provided the original work is properly cited. [DOI: 10.5796/electrochemistry.21-65009].

Keywords : Corrosion Inhibitor, Liquid-phase Deposition, Nitrite-ion Exchanged Ni-Al Layered Double Hydroxide, Equilibrium Reaction of Metal-fluorocomplex

\section{Introduction}

The inhibition of steel corrosion has been studied for a long time, and various anticorrosion techniques have been developed, such as surface coating by galvanizing (zinc metal plating) ${ }^{1}$ and the use of highly corrosion-resistant alloys. ${ }^{2,3}$ Generally, paint-rust prevention has received significant interest, and the development of many excellent paints and coating technologies has dramatically increased the longevity of structural materials. However, anticorrosion coatings need to be reapplied once every several decades. Rust inhibitors for civil engineering structures are mainly divided into

${ }^{\S}$ ECSJ Student Member

${ }^{\S}$ ECSJ Active Member

H. Maki (D) orcid.org/0000-0002-8960-4833

M. Matsui (i) orcid.org/0000-0003-1499-7457

M. Mizuhata (D) orcid.org/0000-0002-4496-2215 two groups: those for new structures and those for old structures. For old rusty structures, the rust must be scraped off the surfaces, followed by curing so that the chemical species causing the corrosion do not adhere until after it is painted. In particular, if $\mathrm{Cl}^{-}$ ions derived from seawater adhere to the substrate at this time, the anticorrosion effect of repainting would be significantly reduced even if the anticorrosion treatment is applied repeatedly, because the $\mathrm{Cl}^{-}$ions cause iron oxidation and pitting corrosion even if they are trapped inside the painted steel; this oxidation reaction is expressed as follows. ${ }^{4,5}$

$$
\mathrm{Fe}+\mathrm{H}_{2} \mathrm{O}+1 / 2 \mathrm{O}_{2} \rightarrow \mathrm{Fe}(\mathrm{OH})_{2}
$$

Here, if the concentration of $\mathrm{Cl}^{-}$is high, the activity of $\mathrm{H}_{2} \mathrm{O}$ increases, and the following reaction predominantly proceeds.

$$
\begin{aligned}
& \mathrm{Fe}(\mathrm{OH})_{2}+1 / 2 \mathrm{H}_{2} \mathrm{O}+1 / 4 \mathrm{O}_{2} \rightarrow \mathrm{Fe}(\mathrm{OH})_{3} \\
& \quad \rightarrow \mathrm{FeOOH}+\mathrm{H}_{2} \mathrm{O}
\end{aligned}
$$


However, if the $\mathrm{Cl}^{-}$concentration is low or additives such as $\mathrm{NO}_{2}{ }^{-}$ ions exist on the steel surface, stable $\mathrm{Fe}_{2} \mathrm{O}_{3}$ protects the interior of the steel. ${ }^{6}$

$$
\begin{aligned}
& \mathrm{Fe}(\mathrm{OH})_{2}+\mathrm{O}_{2} \rightarrow \mathrm{Fe}_{2} \mathrm{O}_{3}+\mathrm{H}_{2} \mathrm{O} \\
& 2 \mathrm{Fe}(\mathrm{OH})_{2}+2 \mathrm{NO}_{2}{ }^{-} \rightarrow 2 \mathrm{NO}+2 \mathrm{Fe}_{2} \mathrm{O}_{3}+\mathrm{H}_{2} \mathrm{O}
\end{aligned}
$$

Nitrite ions are well-known as conventional anticorrosive reagents, and numerous $\mathrm{LiNO}_{2}$ aqueous solutions have been utilized. Conversely, a stabilizer reagent is necessary for the nitrite ion to prevent the slow decomposition of $\mathrm{NO}_{2}{ }^{-}$to $\mathrm{NO}$ gas. ${ }^{7}$

Candidate reagents include anion exchangeable materials, such as layered-double hydroxides (LDHs) ${ }^{8} \mathrm{LDHs}$ are layered inorganic compounds consisting of a metal hydroxide skeleton layer in which a part of the divalent metal cation is replaced by a trivalent metal cation and an interlayer containing anions and $\mathrm{H}_{2} \mathrm{O}$ molecules. The anion in the interlayer can be easily exchanged with an external anion, and owing to this excellent anion-exchange ability, the interlayer anion exchange mechanism has been actively applied in the uptake of harmful anions. One example is its use as a $\mathrm{Cl}^{-}$ absorbent, which causes pitting corrosion. ${ }^{9-13}$ In addition, since LDH can release corrosion inhibitors by anion exchange in the interlayer, many studies have been conducted using LDH as a nano container for corrosion inhibitors. Inorganic inhibitors, such as tungstates, ${ }^{14}$ molybdates, ${ }^{15}$ and phosphates, ${ }^{16}$ and organic inhibitors, such as 2-mercatobenzothiazole (MBT) ${ }^{16} \mathrm{~N}$-benzyl- $p$-toluene sulfonamide (BTS), ${ }^{17}$ and thiazolyl blue tetrazolium bromide (MTT) ${ }^{18}$ have been confirmed to exert a high corrosion-inhibition effect due to two factors: absorption of $\mathrm{Cl}^{-}$and release of the inhibitor. Regarding $\mathrm{NO}_{2}^{-}$, which has been used as an inhibitor for a long time, ${ }^{6,19-24} \mathrm{Xu}$ et al. showed that $\mathrm{NO}_{2}{ }^{-}$-containing $\mathrm{Mg}-\mathrm{Al}$ LDH has a high $\mathrm{Cl}^{-}$absorption capacity and exhibits an excellent corrosion inhibitory effect. ${ }^{25}$ Additionally, Su et al. improved the corrosion resistance of organic coatings by coating $\mathrm{NO}_{2}{ }^{-}$containing $\mathrm{Mg}-\mathrm{Al} \mathrm{LDH}$ with an epoxy resin. ${ }^{26}$ Various kinds of LDH compounds have been applied in the form of particles on metal substrates or developed in the form of a thin film by coprecipitation, ${ }^{27}$ chemical bath deposition (CBD) ${ }^{28}$ sol-gel method, ${ }^{29,30}$ hydrothermal synthesis, ${ }^{31-33}$ liquid-phase deposition (LPD) ${ }^{34-41}$ However, there are several limitations to their practical application, such as the immobilization of particulate LDH on the substrate and the application of $\mathrm{LDH}$ thin films to existing structures.

In this study, we prepared an LDH gel sheet dispersing particulate $\mathrm{Ni}-\mathrm{Al} \mathrm{LDH}$ in a highly adhesive polymer that exerts a rust-preventive effect simply by attaching to a substrate. LDHs such as $\mathrm{Mg}-\mathrm{Al}$ carbonate (hydrotalcite) are commonly prepared by coprecipitation, sol-gel, and hydrothermal synthesis methods. These reactions are generally fast, and the nanoparticles obtained also have a wide particle size distribution, which makes it difficult to disperse them uniformly in the hydrogel. By using a metal-fluorocomplex to prepare a highly dispersed LDH-containing gel in this study, a high crystallized LDH with controlled particle size can be obtained. The LPD method takes advantage of the reaction characteristics of the metal fluorocomplex. Ni species are selected because of their high oxidation potential from $2+$ to $3+$; moreover, it is difficult to oxidize iron from $2+$ to $3+$. Ni-Al LDH using fumed alumina as a carrier was synthesized by LPD. The synthesized LDH was mixed with sodium polyacrylate and water and molded into a flat plate to prepare a gel sheet that could be easily peeled off even after mounting.

Among the various electrochemical measurement methods for corrosion monitoring and evaluation of the corrosion preventive performance of rust inhibitors, ${ }^{42-46}$ this study analyzed the corrosion current using the simplest polarization measurement. Polarization measurements were performed using the gel sheet, and the corrosion-inhibition effect was examined by determining the corrosion potential and corrosion current by the Tafel extrapolation method from the obtained plots. ${ }^{45,46}$ An LDH thin-film sample directly deposited on the iron substrate was also prepared by the LPD method for comparison of the suppression effect. For structures that have been stripped of old paint and exposed, it is necessary to avoid the influences of $\mathrm{Cl}^{-}$ions in salt water in that environment until the paint is reapplied. A gel sheet which can be easily peeled off is expected to contribute to rust-prevention of structures during construction.

\section{Experimental}

\subsection{Pretreatment of steel plate}

An Fe plate was used as a reference substrate for the direct deposition of LDH and the adhesion of LDH-containing polyacrylic gel. First, the as-received steel plate (purity $99.5 \%$, Nilaco Corp.) with a thickness of $0.1 \mathrm{~mm}$ was ultrasonically cleaned in an acetone bath (GR grade, Nacalai Tesque Inc.) for $15 \mathrm{~min}$ to remove the rust preventive oil on its surface. Thereafter, it was immersed in an alkaline degreasing solution containing $2.5 \mathrm{wt} \% \mathrm{NaOH}$ and $7.5 \%$ $\mathrm{Na}_{4} \mathrm{SiO}_{4}$ at ca. $80^{\circ} \mathrm{C}$ for $5 \mathrm{~min}$ and subsequently washed with running water for $10 \mathrm{~min}$. The wet iron plate was washed again in an alkaline scat 20-X (DKS Co. Ltd.) by ultrasonic waves for $10 \mathrm{~min}$, after which it was hydrophilized with running water for $20 \mathrm{~min}$. After confirming that the contact angle with water was $0^{\circ}$, it was stored in deoxidized water to prevent rusting and moved to the next step as soon as possible.

\subsection{LDH thin-film synthesis}

According to the method described in a previous study, $\beta$-nickel hydroxide, as a precursor for LDH preparation, was prepared by the following chemical reactions. ${ }^{34,37}$

Metal-fluorocomplex equilibrium reaction:

$$
\begin{aligned}
& \mathrm{NiF}_{y}{ }^{(y-2)-}+x \mathrm{Al}\left(\mathrm{NO}_{3}\right)_{3}+(2+x) \mathrm{H}_{2} \mathrm{O} \\
& \quad \rightleftarrows\left[\mathrm{Ni}_{1-x} \mathrm{Al}_{x}(\mathrm{OH})_{2}\right] \cdot(\mathrm{OH})_{x}+y \mathrm{~F}^{-}+(2+x) \mathrm{H}^{+}+3 x \mathrm{NO}_{3}{ }^{-}
\end{aligned}
$$

Fluorine scavenging reaction:

$$
\mathrm{Al}^{3+}+6 \mathrm{HF} \rightarrow \mathrm{H}_{3} \mathrm{AlF}_{6}+3 / 2 \mathrm{H}_{2}
$$

Deionized distilled water (hereinafter, distilled water), necessary for dissolving nickel nitrate hexahydrate, $\mathrm{Ni}\left(\mathrm{NO}_{3}\right)_{2} \cdot 6 \mathrm{H}_{2} \mathrm{O}$ (GR grade, Nacalai Tesque Inc.), to yield a saturated aqueous solution, and concentrated ammonia water were diluted five times with a 28 wt $\%$ commercial stock solution (GR grade, Nacalai Tesque Inc.). The precipitate of $\beta-\mathrm{Ni}(\mathrm{OH})_{2}$ was separated by decantation and washed with distilled water.

The LPD reaction mother solution was prepared by thoroughly stirring a wet cake of $\mathrm{Ni}(\mathrm{OH})_{2}$ in a ca. $10 \mathrm{~mol} \mathrm{~L}^{-1} \mathrm{HF}$ solution obtained by diluting a commercial stock solution (46-48 wt\%, GR grade, Stella Chemifa Corp, or FUJIFILM Wako Pure Chemical Corp.) approximately 2.5 times. To reduce the activity of $\mathrm{F}^{-}$, the $\mathrm{NH}_{3}$ aqueous solution mentioned above was added, and the $\mathrm{pH}$ value was adjusted to 8.20 , which is higher than that in a previous study due to the different substrate. ${ }^{37} \mathrm{Al}^{3+}$, which is the source of the second cation component of LDH and the scavenger of $\mathrm{F}^{-}$ions in the LPD equilibrium reaction, was added as an aqueous solution prepared from $\mathrm{Al}\left(\mathrm{NO}_{3}\right)_{3} \cdot 9 \mathrm{H}_{2} \mathrm{O}$. The $\mathrm{Al}\left(\mathrm{NO}_{3}\right)_{3}$ aqueous solution was added so that the concentrations of the dissolved ions after mixing were $\left[\mathrm{Ni}^{2+}\right]=12 \mathrm{mmol} \mathrm{L}^{-1},\left[\mathrm{~F}^{-}\right]=200 \mathrm{mmol} \mathrm{L}^{-1}$, and $\left[\mathrm{Al}^{3+}\right]=$ $2.0 \mathrm{mmol} \mathrm{L}^{-1}$.

For the direct deposition of the LDH thin film on the steel plate by the LPD process, the Fe substrate was dipped in the reaction solution at $50{ }^{\circ} \mathrm{C}$ for $24 \mathrm{~h}$. For the preparation of the $\mathrm{LDH}$ powder, $75 \mathrm{mg}$ of fumed alumina powder, Aeroxide Alu 130, supplied by Nippon Aerosil, was added to $500 \mathrm{~mL}$ of the same reaction solution 
at $50{ }^{\circ} \mathrm{C}$ for $24 \mathrm{~h}$. The obtained composite of $\mathrm{Ni}-\mathrm{Al} \mathrm{LDH}$ coated on the surface of fumed alumina was denoted as FA-LDH.

As shown in Eq. (5), the liquid phase deposition reaction is the one in which hydroxide is deposited by hydrolysis equilibrium of a metal-fluorocomplex. Since the reaction rate is very slow and the supersaturated state is relatively stable, fine particles are not easily generated in a spontaneous uniform nucleation reaction. Here, the addition of fumed alumina nanoparticles significantly accelerates the heterogeneous nucleation reaction of LDH without causing a decrease in purity of LDH due to dissolution. Since fumed alumina has a primary particle size of $10 \mathrm{~nm}$ and has a good dispersion state due to surface charging, it is effective as a heterogeneous nucleus for LDH synthesis.

After the LPD reaction, the as-deposited LDH sample of the thin film on the steel plate and the powder on fumed alumina were obtained by drying the substrate and the precipitate generated at $60^{\circ} \mathrm{C}$.

The shape, morphology, and elemental composition of the Ni-Al LDH coated samples were determined using a JEOL Ltd instrument: a JSM-6335F field emission scanning electron microscope (FESEM) with an energy dispersive X-ray (EDX) spectrometer (JEOL Ltd), JED-2200. A fully automatic multipurpose horizontal X-ray diffractometer (Rigaku Smart Lab) equipped with an $18 \mathrm{~kW} \mathrm{Cu}$ rotating anticathode and $\mathrm{Ge} 220$ channel-cut crystals was used for the structural analysis of the sample.

\subsection{Anion-exchange capacity of LDH}

To measure the ion-exchange capacity of the $\mathrm{Ni}-\mathrm{Al} \mathrm{LDH}$ sample, the $\mathrm{OH}^{-}$ions eluted by ion exchange with $\mathrm{NO}_{2}{ }^{-}$, with the aqueous $\mathrm{NaNO}_{2}$ solution, were quantified by a neutralization titration method using $(\mathrm{COOH})_{2}$ as the standard reagent (GR grade, Nalalai Tesque Inc.). The amount of $\mathrm{NO}_{2}{ }^{-}$inserted into the $\mathrm{LDH}$ was quantified by measuring the amount of change in the $\mathrm{OH}^{-}$concentration in the solution before and after the anion exchange.

\subsection{Preparation of polyacrylic gel}

The polyacrylic gel with and without the FA-LDH powder was prepared as follows. Several additives: $6.0 \mathrm{~g}$ of glycerin $\left(\mathrm{C}_{3} \mathrm{H}_{8} \mathrm{O}_{3}\right.$, GR special grade, Nacalai Tesque Inc.), $0.06 \mathrm{~g}$ of aluminum hydroxide $\left(\mathrm{Al}(\mathrm{OH})_{3}\right.$ : CP grade, Nacalai Tesque Inc.), and $0.06 \mathrm{~g}$ of tartaric acid $\left((\mathrm{CH}(\mathrm{OH}) \mathrm{COOH})_{2}\right.$ : GR Grade, Nacalai Tesque Inc.) were added to $1.2 \mathrm{~g}$ of sodium polyacrylate, $\left(\mathrm{C}_{3} \mathrm{H}_{3} \mathrm{NaO}_{2}\right)_{n}$, supplied by Toagosei Co., Ltd. The mixed reagents were dissolved in $12.68 \mathrm{~g}$ of distilled water and mixed for $30 \mathrm{~min}$ to obtain $20 \mathrm{~g}$ of the polyacrylic gel. For preparing a sample containing FA-LDH, 0.2$0.6 \mathrm{~g}$ of FA-LDH powder was mixed before kneading the gel raw materials. The standard mass of FA-LDH is 0.4 .

\subsection{Polarization measurement for determining the corrosion potentials and current}

To measure the corrosion-inhibition effect of the obtained sample, a three-electrode type measuring cell was prepared, and electrochemical measurements were performed. Polarization measurements were performed using steel substrates with and without the $\mathrm{Ni}-\mathrm{Al}$ LDH thin films as the working electrodes. The substrate was covered with masking tape to create an exposed area of $1 \mathrm{~cm}^{2}$. An $\mathrm{Ag} / \mathrm{AgCl}$ reference electrode was employed with a saturated $\mathrm{KCl}$ agar solution as the salt bridge. A Pt plate with dimensions of $25 \mathrm{~mm} \times 25 \mathrm{~mm}$ was used as the counter electrode. When using an Fe substrate coated with $\mathrm{LDH}$ as the working electrode, a $3.5 \mathrm{wt} \%$ $\left(0.6 \mathrm{~mol} \mathrm{~L}^{-1}\right)$ aqueous $\mathrm{NaCl}$ solution with a concentration corresponding to that in seawater was used as the electrolyte. Contrarily, when using a polyacrylic gel swollen with the $3.5 \mathrm{wt} \%$ aqueous $\mathrm{NaCl}$ electrolyte solution as the anticorrosion sheet, an ordinary $\mathrm{Fe}$ plate was used as the working electrode. The polyacrylic gel was molded into a cube of $1 \mathrm{~cm}^{3}$ to keep the contact area and thickness with the working electrode constant, and the sample was immersed in a $3.5 \mathrm{wt} \% \mathrm{NaCl}$ solution before the measurement because the measurement was performed in an environment with sufficient $\mathrm{Cl}^{-}$. A schematic of the measurement for the system using the LDHcoated steel plate and polyacrylic gel is shown in Fig. S1.

Five minutes after immersing the steel plate in aqueous $\mathrm{NaCl}$ solution or attaching polyacrylic gel, the $I-V$ curves for the polarization phenomena were measured using an IVIUM Compact Stat Plus. The scanning range was $-1.0 \mathrm{~V}$ to $1.0 \mathrm{~V}$, and the scan rate was $10 \mathrm{mV} \mathrm{s}^{-1}$. The corrosion potential $\left(E_{\text {corr }}\right)$ and corrosion current density $\left(I_{\text {corr }}\right)$ were determined from the slope of the linear polarization curve in the low-polarization region on a logarithmic scale. Since the corrosion rate is proportional to the corrosion current density, it is generally considered that suppressing the corrosion current density leads to corrosion protection for metal surfaces. ${ }^{6,42}$

\section{Results and Discussion}

\subsection{Surface morphology of $\mathrm{Ni}-\mathrm{Al}$ LDH}

Figure 1 shows the SEM image of the prepared $\mathrm{Ni}-\mathrm{Al} \mathrm{LDH}$ deposited on a steel plate and fumed alumina by the LPD process. The sub-micrometer-ordered dense structure with a network shape even on metal surfaces and oxide powders is similar in appearance to those in our previous studies, where the LDH sample was deposited on a glass substrate, ${ }^{34}$ carbon surface, ${ }^{35,36,38-40}$ or nickel metal. ${ }^{41}$ Since fumed alumina acts as a crystal nucleus for the precipitation of $\mathrm{LDH}$, it was confirmed by gravimetric analysis that the content of fumed alumina after preparation was $15 \mathrm{wt} \%$ or less of the mass of FA-LDH. The composition of the obtained Ni-Al LDH
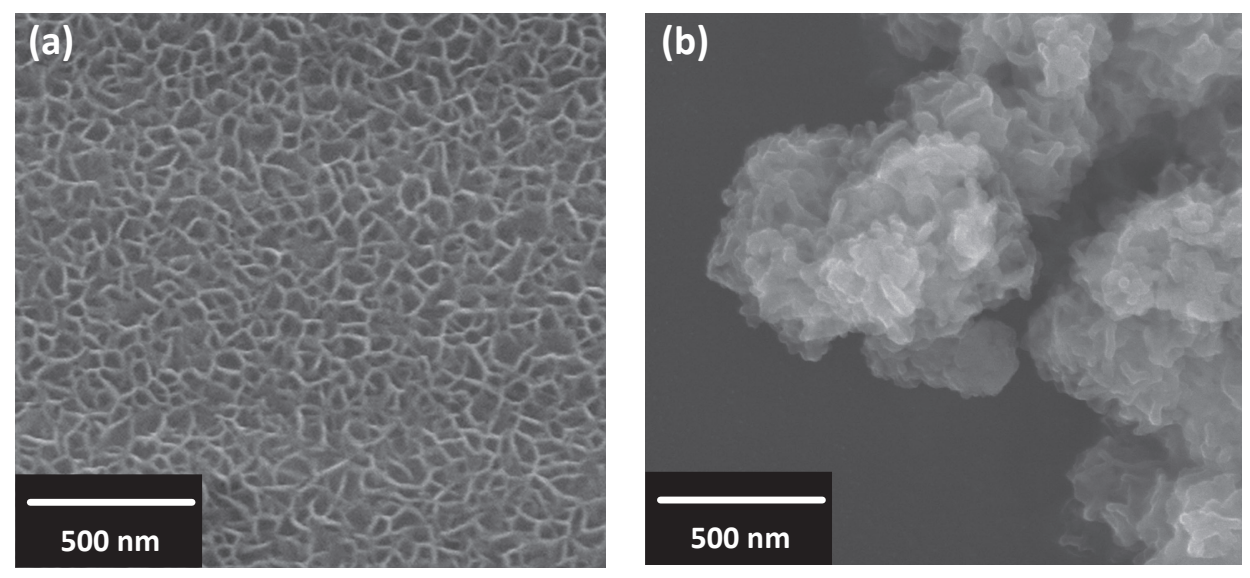

Figure 1. SEM image of the prepared Ni-Al LDH deposited on (a) a steel plate and (b) fumed alumina by the LPD process. 
is typically $\left[\mathrm{Ni}(\mathrm{II})_{0.69} \mathrm{Al}(\mathrm{III})_{0.31}(\mathrm{OH})_{2}\right] \mathrm{OH}_{0.31}$ in $\mathrm{OH}^{-}$-type $\mathrm{LDH}$, which is in agreement with the results of previous studies. The amounts of ion-exchanged $\mathrm{NO}_{2}$ ions are $z=0.0083,0.0171$, and 0.0242 in $\left[\mathrm{Ni}(\mathrm{II})_{0.69} \mathrm{Al}(\mathrm{III})_{0.31}(\mathrm{OH})_{2}\right]\left(\mathrm{NO}_{2}\right)_{z}(\mathrm{OH})_{0.31-z}$, for the $\mathrm{NaNO}_{2}$ solution concentrations of 1,2 , and $5 \mathrm{~mol} \mathrm{~L}^{-1}$, respectively. The amount of ion-exchanged $\mathrm{NO}_{2}$ is small, and nitrous acid should be used to increase the ion-exchange rate. However, nitrous acid is very unstable and easily undergoes self-decomposition, as shown in Eq. (7). ${ }^{7}$

$$
3 \mathrm{HNO}_{2} \rightarrow \mathrm{HNO}_{3}+2 \mathrm{NO}+\mathrm{H}_{2} \mathrm{O}
$$

Consequently, the $\mathrm{NaNO}_{2}$ solution was chosen for this procedure. Before and after the ion-exchange reaction, the distance of the 003 plane of LDH, $d_{003}$, changed slightly with the ionic size of the exchanged anions, as shown in Fig. S2. The slight change in $d_{003}$ from $773 \mathrm{pm}$ to $776 \mathrm{pm}$ highlighted the results of a small amount of ion exchange, even though the anionic radii are different between $\mathrm{OH}^{-}\left(r_{\mathrm{OH}}{ }^{-}=137 \mathrm{pm}\right)$ and $\mathrm{NO}_{2}{ }^{-}\left(r_{\mathrm{NO}_{2}}{ }^{-}=187 \mathrm{~nm}\right)$, caused by a small amount of exchanged nitrite ions.

\subsection{Corrosion-inhibition effect of $\mathrm{NO}_{2}^{-}$-exchanged $\mathrm{Ni}-\mathrm{Al} \mathrm{LDH}$ on the steel plate}

The corrosion-inhibition effect of the coated Ni-Al LDH thin film was examined using the Tafel plot obtained by polarization measurements for a bare steel plate. The Tafel plots for the system using Ni-Al LDH coated steel plates are shown in Fig. 2, and the calculated values of the corrosion and pitting potentials, as well as the corrosion current, are shown in Table 1 . The corrosion current when $\mathrm{OH}^{-}$-exchanged $\mathrm{LDH}$ was used is $1.7 \mu \mathrm{A}$, which is approximately $1 / 8$ th the current $(13 \mu \mathrm{A})$ obtained when a bare steel substrate is used. It is considered that this is because LDH physically prevents the attack of $\mathrm{Cl}^{-}$ions and the decrease in the $\mathrm{Cl}^{-}$ concentration near the surface of the substrate due to ion exchange. ${ }^{6}$

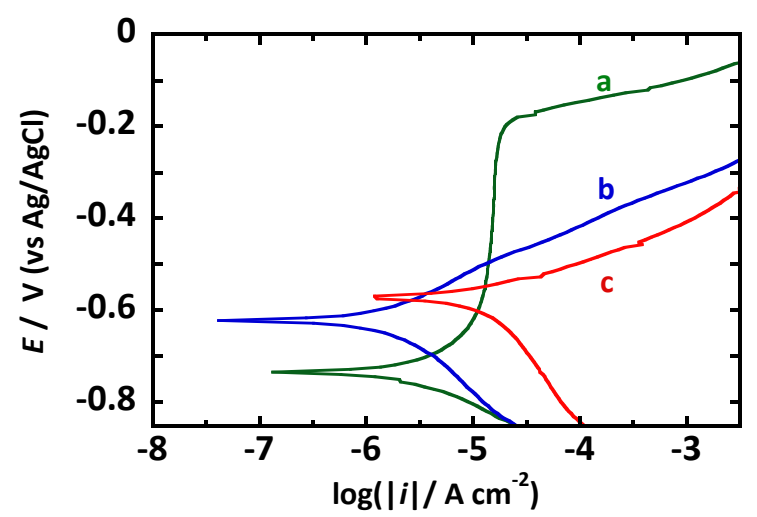

Figure 2. Tafel plots of the steel plate polarized in $3.5 \mathrm{wt} \%$ aqueous $\mathrm{NaCl}$ solution. Working electrode: (a) $\mathrm{NO}_{2}{ }^{-}$-exchanged $\mathrm{Ni}-\mathrm{Al}$ LDH coated steel plate, (b) $\mathrm{OH}^{-}$-exchanged $\mathrm{Ni}-\mathrm{Al} \mathrm{LDH}$ coated steel plate, and (c) degreased steel plate. To avoid corrosion of the metal surface, the potential was swept to the cathodic side until immediately before hydrogen gas was generated first. After that, it was reverted and swept toward the anodic side until a decrease in current due to the corrosion and pitting potentials or passivation occurred. The following polarizing curves were obtained via the same procedure.
In addition, when a steel sheet coated with $\mathrm{NO}_{2}{ }^{-}$-exchanged $\mathrm{LDH}$ was used, although the corrosion current value increased slightly, it was found that the anode current was suppressed in the high potential region up to about $-0.2 \mathrm{~V}$ vs. $\mathrm{Ag} / \mathrm{AgCl}$. This indicates that stable passivation occurred due to the $\mathrm{NO}_{2}{ }^{-}$exchanged LDH. This result is due to the re-passivation of $\mathrm{Fe}^{2+}$ by the released $\mathrm{NO}_{2}{ }^{-}$from $\mathrm{LDH}$, in addition to the absorption of $\mathrm{Cl}^{-}$by anion exchange into LDH. ${ }^{25}$ Since the value of $I_{\text {corr }}$, shown in Table 1, was similar to that of the $\mathrm{OH}^{-}$-exchanged $\mathrm{LDH}$, it was confirmed that the corrosion rate also decreased. When the $\mathrm{OH}^{-}$ion is replaced with the $\mathrm{NO}_{2}{ }^{-}$ion, the pitting potential is remarkably increased while the corrosion current is slightly increased. It is suggested that the passivation layer itself of the steel sheet is slightly damaged. It was confirmed that $\mathrm{NO}_{2}{ }^{-}$-exchanged $\mathrm{LDH}$ exerts a significant corrosion-inhibiting effect by the direct coating of Ni-Al $\mathrm{LDH}$, which is comparable with the results of previous studies. ${ }^{25,26}$

\subsection{Corrosion-inhibition effect of $\mathrm{NO}_{2}{ }^{-}$-exchanged FA-LDH}

Although it is effective to coat LDH directly on new structural materials, it is necessary to confirm the effect of the gel sheet applied after removing rust, since it is difficult to deposit LDH directly on used steel. To estimate the corrosion-inhibition effect of LDH coated on fumed alumina (FA) dispersed in polyacrylic gel, polarization curves obtained using a polyacrylic gel containing FA-LDH as the electrolyte are shown in Fig. 3. The corrosion and pitting potentials, as well as the corrosion current, in the presence of FA-LDH are shown in Table 2. The Tafel plots indicate that the anode current is suppressed and a clear passivation region exists in the system incorporating the gel-containing $\mathrm{LDH}$, in contrast to the case of the

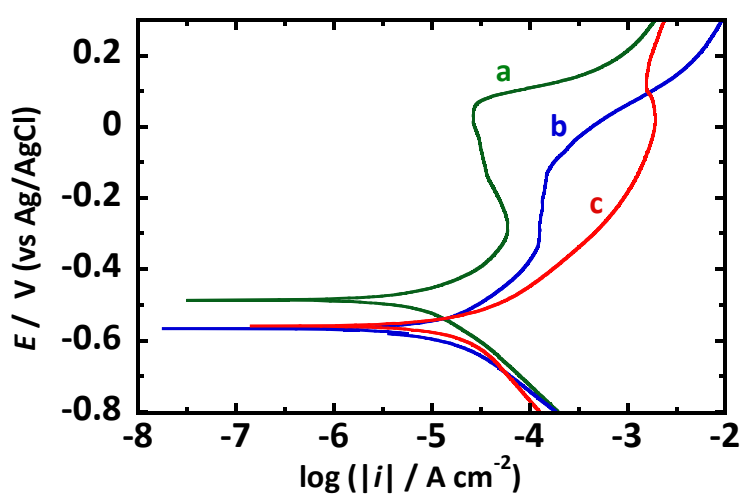

Figure 3. Tafel plots of the steel-plate-covered polyacrylic gel containing FA-LDH powder. Attached gel component: (a) $\mathrm{NO}_{2}{ }^{-}$exchanged FA-LDH, (b) $\mathrm{OH}^{-}$-exchanged FA-LDH, and (c) no $\mathrm{LDH}$. The polyacrylic gel was fully swollen by the $3.5 \mathrm{wt} \%$ aqueous $\mathrm{NaCl}$ solution under the initial condition before polarization.

Table 2. Corrosion and pitting potentials and the corrosion current for the sample indicated in Fig. 3.

\begin{tabular}{lcrc}
\hline Working Electrode & $E_{\text {corr }} / \mathrm{mV}$ & $E_{\text {pit }} / \mathrm{mV}$ & $I_{\text {corr }} / \mu \mathrm{A}$ \\
\hline (a) $\mathrm{Fe} / \mathrm{NO}_{2}{ }^{-}$-exchanged FA-LDH & -504 & 41 & 13.0 \\
(b) $\mathrm{Fe} / \mathrm{OH}^{-}$-exchanged FA-LDH & -588 & -127 & 18.7 \\
(c) $\mathrm{Fe} /$ polyacrylic gel with $\mathrm{NaCl}$ aq. & -584 & 117 & 25.8 \\
\hline
\end{tabular}

Table 1. Corrosion and pitting potentials and the corrosion current for the sample indicated in Fig. 2.

\begin{tabular}{lcccc}
\hline Working Electrode & $E_{\text {corr }} / \mathrm{mV}$ & $E_{\text {pit }} / \mathrm{mV}$ & $E_{\text {pit }}-E_{\text {corr }} / \mathrm{mV}$ & $I_{\text {corr }} / \mu \mathrm{A}$ \\
\hline (a) $\mathrm{Fe} / \mathrm{NO}_{2}{ }^{-}$-Exchanged LDH & -734 & -190 & 531 & 2.80 \\
(b) $\mathrm{Fe} / \mathrm{OH}^{-}$-Exchanged LDH & -608 & -503 & 108 & 1.70 \\
(c) Degreased Fe & -568 & -550 & 18 & 13.0 \\
\hline
\end{tabular}


polyacrylic gel containing only the aqueous $\mathrm{NaCl}$ solution. This tendency is the same as that for the system incorporating the LDHcoated steel plate, as shown in Fig. 2. In particular, $\mathrm{NO}_{2}{ }^{-}$exchanged FA-LDH has a more suppressed anode current, and the $I_{\text {corr }}$ value is $13.0 \mu \mathrm{A} \mathrm{cm}^{-1}$, which is approximately half that without $\operatorname{LDH}\left(25.8 \mu \mathrm{A} \mathrm{cm}^{-1}\right)$, as shown in Table 2. Due to the lack of physical protection from the attack of $\mathrm{Cl}^{-}$, the suppression efficiency of FA-LDH is lower than that of LDH deposited on the steel plate directly, although its $I_{\text {corr }}$ suppression efficiency is high. $\mathrm{Ni}-\mathrm{Al}$ LDH shows a high corrosion-inhibition effect because it has two functions: anion exchange and repassivation by $\mathrm{NO}_{2}^{-}$release, even in a polyacrylic gel.

Regarding the variations in the current density during surface corrosion by constant potential electrolysis at $-0.3 \mathrm{~V}$ vs. $\mathrm{Ag} / \mathrm{AgCl}$ and the corrosion state of the steel plate during electrolysis, the results of the gel impregnated with salt and the gel impregnated with LDH were obtained, as shown in Fig. S3a. Additionally, the SEM images of the surface of the steel substrate at that time are shown in Fig. S3b. For the gel sample impregnated with the $\mathrm{NaCl}$ solution, a gradual decrease in the current due to the polarization of the ionic species was observed. Significant pitting corrosion was observed on the sample surface. Contrarily, in the gel sample containing LDH, a low current, which is considered to be caused by $\mathrm{NO}_{2}{ }^{-}$, was observed at the initial stage, and this low current was maintained without any increase. Almost no evidence of corrosion was observed on the surface of the sample. Here, it was shown that the $\mathrm{NO}_{2}{ }^{-}-$ exchanged $\mathrm{Ni}-\mathrm{Al} \mathrm{LDH}$ has a very effective rust-preventive effect.

\subsection{Dependence of anticorrosive effect on the amount of $\mathrm{NO}_{2}$ exchanged FA-LDH in polyacrylic gel}

The results of polarization measurements with varying amounts of the $\mathrm{NO}_{2}{ }^{-}$-exchanged FA-LDH added during the preparation of the polyacrylic gel are shown in Fig. 4, and their corrosion and pitting potentials, as well as the corrosion current, are shown in Table 3. The anodic current was suppressed as the LDH content

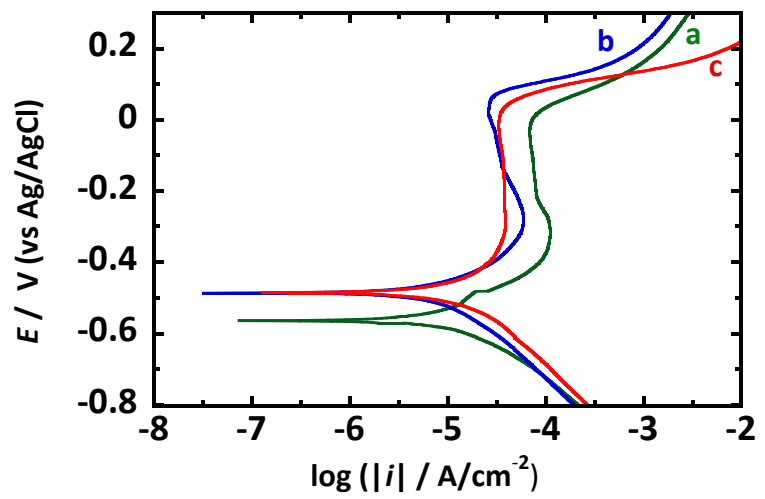

Figure 4. Variation of the Tafel plots with the LDH content for the steel-plate-covered polyacrylic gel containing FA-LDH powder. Concentrations of the added LDH: (a) 1, (b) 2, and (c) $3 \mathrm{wt} \%$. The polyacrylic gel was fully swollen by the $3.5 \mathrm{wt} \%$ aqueous $\mathrm{NaCl}$ solution under the initial condition before polarization.

Table 3. Corrosion and pitting potentials and the corrosion current for the sample indicated in Fig. 4.

\begin{tabular}{cccrc}
\hline \multicolumn{2}{c}{$\begin{array}{c}\text { Amount of } \\
\text { Added LDH/wt\% }\end{array}$} & $E_{\text {corr }} / \mathrm{mV}$ & $E_{\text {pit }} / \mathrm{mV}$ & $I_{\text {corr }} / \mu \mathrm{A}$ \\
\hline (a) & 1 & -586 & -41 & 16.2 \\
(b) & 2 & -504 & 41 & 13.0 \\
(c) & 3 & -491 & -64 & 11.5 \\
\hline
\end{tabular}

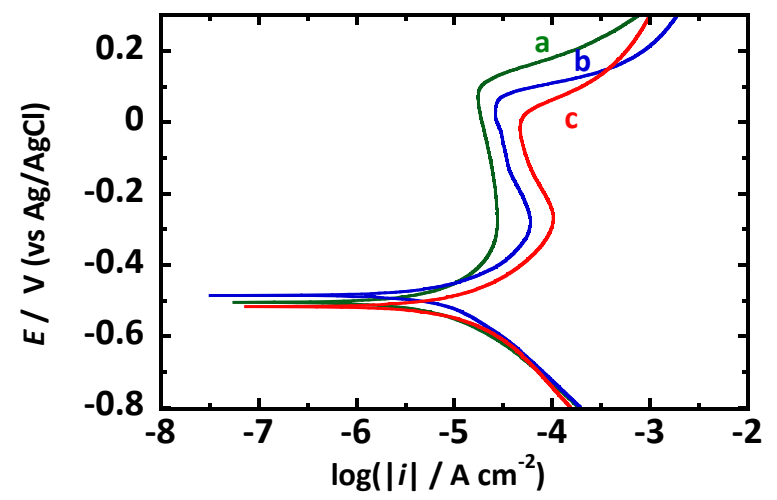

Figure 5. Variation of the Tafel plots with LDH densities for the steel-plate-covered polyacrylic gel containing FA-LDH powder. Thicknesses of the gel sample: (a) 5, (b) 10 , and (c) $20 \mathrm{~mm}$. Concentrations of the added LDH: (a) 4, (b) 2, and (c) $1 \mathrm{wt} \%$. The polyacrylic gel was fully swollen by the $3.5 \mathrm{wt} \%$ aqueous $\mathrm{NaCl}$ solution under the initial condition before polarization.

increased, and the lowest $I_{\text {corr }}$ was observed in the gel containing $3 \mathrm{wt} \%$ LDH; however, the corrosion current did not decrease significantly. This result was expected because of the increase in the $\mathrm{Cl}^{-}$absorption amount and $\mathrm{NO}_{2}^{-}$release amount as the anion exchange amount in the gel increased.

Although the improvement of the corrosion-inhibition effect by increasing the amount of released $\mathrm{NO}_{2}{ }^{-}$has been clarified, not all of the $\mathrm{NO}_{2}{ }^{-}$ions might react with $\mathrm{Fe}^{2+}$ even if the amount of $\mathrm{LDH}$ in the gel is increased. That is, the rust-preventive effect cannot be exhibited unless the $\mathrm{NO}_{2}^{-}$ions can reach the vicinity of the substrate. Therefore, polarization measurements were performed by changing the thickness of the gel used for the measurement to investigate the influence of the diffusion rate of ions in the gel on the corrosion inhibition with the same total concentration of LDH. As shown in Fig. 5, the thickness of the gel sheet and the LDH content were adjusted so that the total concentration of LDH was constant, and only the effect of the diffusion rate of ions was the focus. The results revealed that the anodic current decreased with the thickness. In addition, the smallest $I_{\text {corr }}$ value of $9.7 \mu \mathrm{A} \mathrm{cm}^{-2}$ was obtained for a $0.5 \mathrm{~cm}$ gel sheet, and the gel with a low thickness had a high inhibitory effect. These results suggest that when the same total amount of $\mathrm{LDH}$ is dispersed, its density affects the amount of $\mathrm{NO}_{2}{ }^{-}$ ions that reach the surface of the steel plate. Due to the low diffusion rate of the $\mathrm{NO}_{2}{ }^{-}$ions released by anion exchange, they take a long time to reach the iron surface inside the thick gel. For the relatively thin gel sheet, $\mathrm{NO}_{2}{ }^{-}$is released near the surface; thus, it is consumed at a high rate since it reacts rapidly with $\mathrm{Fe}^{2+}$. However, as the thickness increases, the amount of $\mathrm{NO}_{2}{ }^{-}$reacting with $\mathrm{Fe}^{2+}$ ions decreases, and the anticorrosion effect also decreases. Consequently, the corrosion-inhibition effect depends on both the LDH concentration and its density in the gel sheet.

\subsection{Stability of $\mathrm{NO}_{2}^{-}$ions in the polyacrylic gel containing $\mathrm{FA}-$ $\mathrm{LDH}$}

$\mathrm{NO}_{2}{ }^{-}$ions are unstable because they may decompose while producing $\mathrm{NO}$ gas due to equilibrium with $\mathrm{H}^{+}$ions under atmospheric exposure. ${ }^{7}$ It is expected that $\mathrm{LDH}$ might stabilize the exchanged $\mathrm{NO}_{2}{ }^{-}$ions via the interaction between the $\mathrm{LDH}$ skeleton and $\mathrm{NO}_{2}{ }^{-}$ions when an electrolyte solution containing $\mathrm{NO}_{2}{ }^{-}$ions is used as a rust-preventive coating. Therefore, a comparison was made with the system of the gel impregnated with only the $\mathrm{NaNO}_{2}$ solution. The gel sample containing $\mathrm{NO}_{2}{ }^{-}$was obtained by immersing the polyacrylic gel into a $2 \mathrm{mmol} \mathrm{L}^{-1} \mathrm{NaNO}_{2}$ aqueous solution to compare the inhibitory effect of $\mathrm{NO}_{2}{ }^{-}$-exchanged FA- 


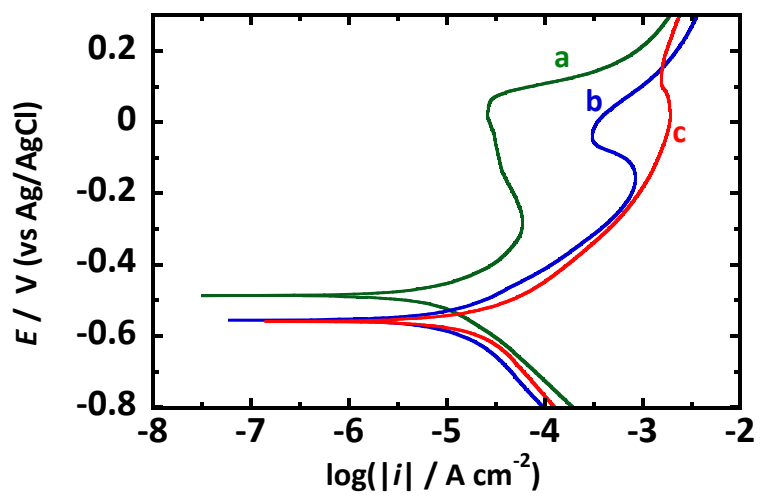

Figure 6. Changes in the Tafel plots due to the differences in the $\mathrm{NO}_{2}{ }^{-}$-ion status for the steel-plate-covered polyacrylic gel. State of the $\mathrm{NO}_{2}{ }^{-}$ion: (a) inserted in FA-LDH, (b) immersed in polyacrylic gel without FA-LDH, and (c) no $\mathrm{LDH}$. The polyacrylic gel was fully swollen by the $3.5 \mathrm{wt} \%$ aqueous $\mathrm{NaCl}$ solution under the initial condition before polarization. Sample (b) was dipped into a $1 \mathrm{~mol} \mathrm{~L}^{-1}$ aq. $\mathrm{NaNO}_{2}$ solution after swelling in an $\mathrm{NaCl}$ solution.

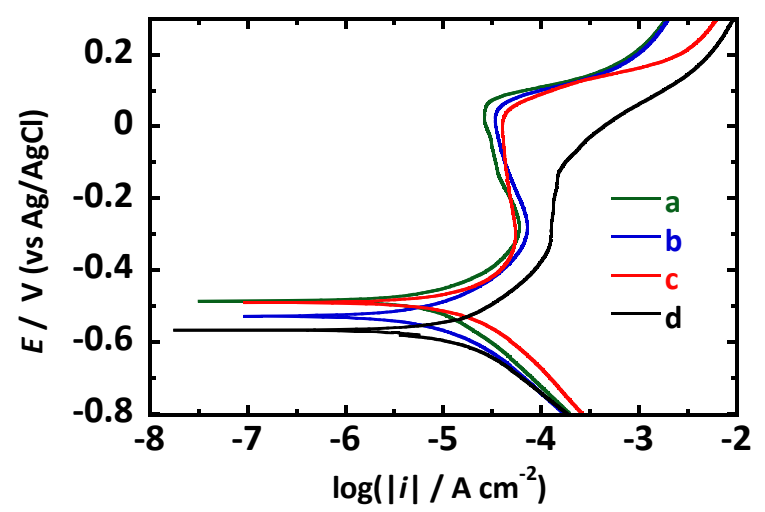

Figure 7. Durability of the $\mathrm{NO}_{2}{ }^{-}$exchanged FA-LDH shown on the Tafel plots for the steel-plate-covered polyacrylic gel containing FA-LDH powder. Measured after (a) 3 days, (b) 14 days, (c) 1 month, after preparation, and (d) immediately for the $\mathrm{OH}^{-}$exchanged FA-LDH and swollen by the $3.5 \mathrm{wt} \%$ aq. $\mathrm{NaCl}$ solution.

LDH with that in the case of using nitrous acid alone. The immersion time was adjusted so that the concentration of $\mathrm{NO}_{2}{ }^{-}$in the gel was similar to the maximum concentration of $\mathrm{NO}_{2}{ }^{-}$released from the LDH. As shown in Fig. 6, the system containing $\mathrm{NO}_{2}{ }^{-}$ ions alone exhibits partial current suppression; however, the effect of $\mathrm{NO}_{2}{ }^{-}$is noticeably less significant than that of the $\mathrm{NO}_{2}{ }^{-}$-exchanged FA-LDH. From this control experiment, the combination of LDH and $\mathrm{NO}_{2}{ }^{-}$ions was confirmed to exert a high corrosion-inhibiting effect with high stability.

As described above, if $\mathrm{NO}_{2}{ }^{-}$ions disappear immediately, the corrosion-inhibition effect becomes unstable, which impedes the rust-preventive function of the coating. The long-term stability of $\mathrm{NO}_{2}{ }^{-}$-exchanged $\mathrm{FA}-\mathrm{LDH}$ was verified by measuring the polarization of the gel using an LDH sample left for a certain period after the anion-exchange reaction. If the nitrous acid is depleted, and the passivation promotion effect is not exerted, a plot similar to that for the $\mathrm{OH}^{-}$-exchanged FA-LDH, whose inhibitory effect occurred via $\mathrm{Cl}^{-}$absorption, would be obtained. The obtained data in Fig. 7 show that only a slight difference was observed between the 1month sample and the 3-day sample after the anion exchange, and the anticorrosive effect was still considerable. The persistent effect is suggested to be because $\mathrm{NO}_{2}{ }^{-}$, which is unstable in solution, is incorporated into LDH and stabilized by electrostatic interactions.
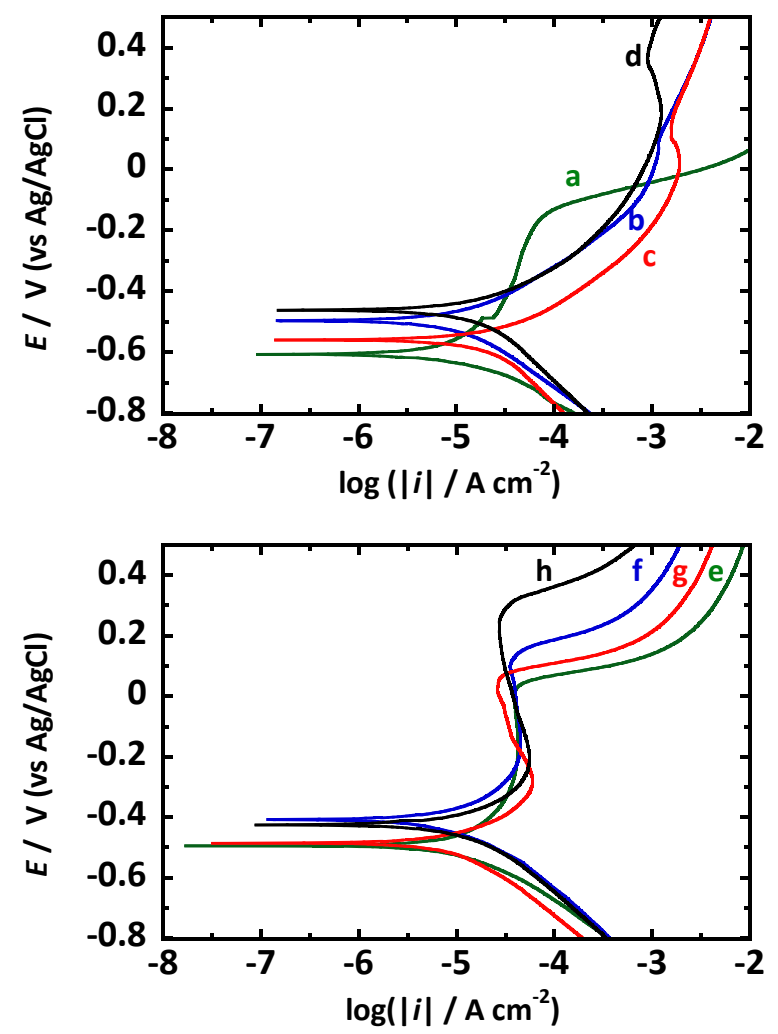

Figure 8. Concentration dependence of the Tafel plots for the steel-plate-covered polyacrylic gel in the aq. $\mathrm{NaCl}$ solution (a-d) without and $(\mathrm{e}-\mathrm{h})$ with $\mathrm{NO}_{2}{ }^{-}$-exchanged FA-LDH. Concentrations of $\mathrm{NaCl}$ : (a, e) $6 \mathrm{molL}^{-1},(\mathrm{~b}, \mathrm{f}) 1 \mathrm{molL}^{-1}$, (c, g) $0.6 \mathrm{~mol} \mathrm{~L}^{-1}$ $(3.5 \mathrm{wt} \%)$, and $(\mathrm{d}, \mathrm{h}) 0.1 \mathrm{~mol} \mathrm{~L}^{-1}$. The polyacrylic gel was fully swollen by each concentration of the aq. $\mathrm{NaCl}$ solution under the initial condition before polarization.

\subsection{Influence of $\mathrm{Cl}^{-}$ion and $\mathrm{pH}$ on the rust-prevention efficiency of FA-LDH}

In the natural environment, the concentration of $\mathrm{Cl}^{-}$is not constant, and we can easily predict that it will frequently change due to the changes in the weather. Considering that an increase in the $\mathrm{Cl}^{-}$concentration affects the suppression effect due to the conductivity increase caused by the activities of $\mathrm{Cl}^{-}$and counter cations, the results of the measurement involving swelling the gel with various concentrations of aqueous $\mathrm{NaCl}$ solution are shown in Fig. 8. When the LDH-free gels were compared, the largest flowing anode current was obtained at approximately $0.6 \mathrm{~mol} \mathrm{~L}^{-1}$, corresponding to the concentration of seawater ( $3.5 \mathrm{wt} \% \mathrm{NaCl}$ solution). This may be related to the concentration of dissolved oxygen in the gel sample. In the high-concentration region, the progress of corrosion should be delayed as the equilibrium solubility of oxygen decreases. In addition, when a saturated $\mathrm{NaCl}$ aqueous solution (approximately $6 \mathrm{~mol} \mathrm{~L}^{-1}$ ) was used, the anode current increased rapidly around $0 \mathrm{~V}$ vs. $\mathrm{Ag} / \mathrm{AgCl}$, which is considered to be caused by the oxidation of $\mathrm{Cl}^{-}$ions. Conversely, for the gel containing $\mathrm{NO}_{2}$-exchanged $\mathrm{Ni}-\mathrm{Al} \mathrm{LDH}$, the anode current was suppressed at any concentration, and the influence of the $\mathrm{Cl}^{-}$concentration was not significant. We considered these results to be related to the rate of anion exchange, which is sensitive to the concentration of external ions; the higher the concentration, the higher the rate. Therefore, the absorption of more $\mathrm{Cl}^{-}$ions was considered to be due to the higher exchange rate than that in the $\mathrm{Cl}^{-}$rich system.

To confirm the stability of LDH under various $\mathrm{pH}$ conditions, the polyacrylic gel was swollen with $\mathrm{NaCl}$ aqueous solutions of various $\mathrm{pH}$ values adjusted using dilute $\mathrm{HCl}$ and $\mathrm{NaOH}$. As $\mathrm{LDH}$ was 


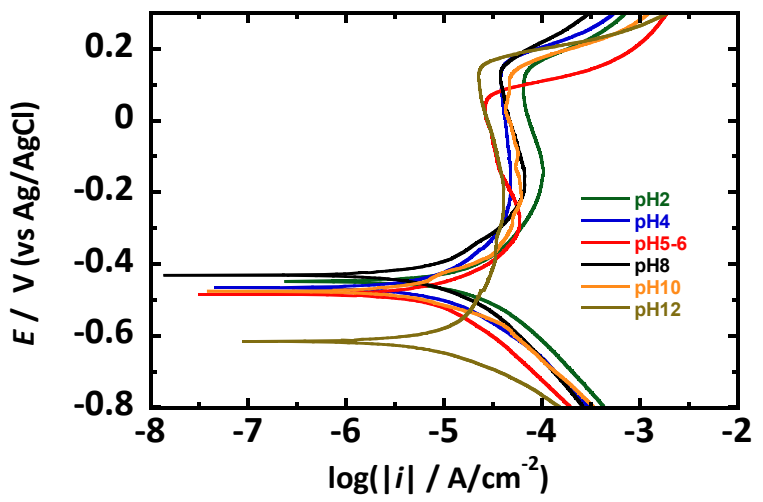

Figure 9. $\mathrm{pH}$ dependence of the Tafel plots for the steel-platecovered polyacrylic gel containing FA-LDH powder in aq. $\mathrm{NaCl}$ solution. The $\mathrm{pH}$ of each solution was adjusted between 2 and 12 . The polyacrylic gel was fully swollen by each concentration of the aq. $\mathrm{NaCl}$ solution under the initial condition before polarization.

synthesized in a basic medium, it should be unstable in an acidic solution, and its corrosion-inhibition effect should be reduced. However, Fig. 9 shows that it suppresses the current even when immersed in an acidic solution. These data suggest that LDH is stable and exerts an inhibitory effect even in an acidic environment. At $\mathrm{pH} 12$, the passivation region was much larger than those at the other $\mathrm{pH}$ values, and the passivation was stable.

\section{Conclusion}

$\mathrm{NO}_{2}{ }^{-}$-ion-exchanged $\mathrm{Ni}-\mathrm{Al}$ layered double hydroxide (LDH) was deposited on a steel plate and fumed alumina powder to prepare anticorrosive materials for the rust prevention of steel surfaces. The amount of $\mathrm{NO}_{2}{ }^{-}$exchanged in the $\mathrm{Ni}-\mathrm{Al} \mathrm{LDH}$ was in the range of $\left.y=0.0083-0.0242\left[\mathrm{Ni}(\mathrm{II})_{0.69} \mathrm{Al}(\mathrm{III})_{0.31} \mathrm{OH}\right)_{2}\right]\left(\mathrm{NO}_{2}\right)_{y}(\mathrm{OH})_{0.31-y}$ in the $\mathrm{OH}^{-}$-type $\mathrm{LDH}$, corresponding to a ratio of $2.7-7.8 \%$ of the total exchangeable anions. The results of the corrosion measurements with a sodium polyacrylic gel sheet containing $\mathrm{Ni}-\mathrm{Al} \mathrm{LDH}$ highlighted the highly effective corrosion inhibition effect of the gel sheet with $\mathrm{NO}_{2}^{-} \mathrm{LDH}$. The analysis of the influence of the gel thickness revealed that the diffusion rate of ions affects the corrosion-inhibition effect. Normally, unstable $\mathrm{NO}_{2}{ }^{-}$ions exert a stable rust-preventive effect for more than one month in the presence of LDH. Compared to that of the gel soaked directly in aq. $\mathrm{NaNO}_{2}$, the gel containing LDH exerted a higher inhibitory effect. This rust prevention by $\mathrm{NO}_{2}{ }^{-}$-exchanged $\mathrm{Ni}-\mathrm{Al} \mathrm{LDH}$ was effective regardless of whether it was deposited directly on the steel sheet or dispersed into a polyacrylic gel. A good rust preventive effect was also observed in the hydrous LDH gel sheet in which arbitrary chloride ions were dissolved under atmospheric exposure. This indicates that it is an effective rust-preventive material for both new steel sheets and for curing the surfaces of existing iron materials that have been subjected to rust-removal processes.

\section{Supporting Information}

The Supporting Information is available on the website at DOI: https://doi.org/10.5796/electrochemistry.21-65009.

\section{Acknowledgments}

This study was supported by Yokogawa Bridge Holdings Corp. The authors thank Mr. Susumu Inokuchi of YBHD for useful discussion. The authors thank Toagosei Corp. for providing the polyacrylic gel sample and Nippon Aerosil Co., Ltd. for providing fumed alumina. Professor Yoshiyuki Komoda and Dr. Kosuke Suzuki of Kobe University helped the authors to optimize the preparation of the polyacrylic gel composite with LDH powder.

\section{References}

1. S. M. A. Shibli, B. N. Meena, and R. Remya, Surf. Coat. Technol., 262, 210 (2015).

2. G. Song, A. Andrej, X. Wu, and B. Zhang, Corros. Sci., 40, 1769 (1998).

3. T. Dursun and C. Soutis, Mater. Des., 56, 862 (2014).

4. W. H. Walker, A. M. Cederholm, and L. N. Bent, J. Am. Chem. Soc., 29, 1251 (1907).

5. J. Kassim, T. Baird, and J. R. Fryer, Corros. Sci., 22, 147 (1982)

6. Y. Zhou and Y. Zuo, Appl. Surf. Sci., 353, 924 (2015).

7. Y. Kameoka and R. L. Pigford, Ind. Eng. Chem. Fundam., 16, 163 (1977)

8. F. Cavani, F. Triffiro, and A. S. Vaccari, Catal. Today, 11, 173 (1991).

9. H. Zaghouane-Boudiaf, M. Boutahala, and L. Arab, Chem. Eng. J., 187, 142 (2012).

10. P.-P. Huang, C.-Y. Cao, F. Wei, Y.-B. Suna, and W.-G. Song, RSC Adv, 5, 10412 (2015).

11. K. Yang, L.-G. Yan, Y.-M. Yang, S.-J. Yu, R.-R. Shan, H.-Q. Yu, B.-C. Zhu, and B. Du, Sep. Purif. Technol., 124, 36 (2014).

12. J. Xu, Y. Song, Q. Tan, and L. Jiang, J. Mater. Sci., 52, 5908 (2017).

13. F. Zhang, Z.-G. Liu, R.-C. Zeng, S.-Q. Li, H.-Z. Cui, L. Song, and E.-H. Han, Surf. Coat. Technol., 258, 1152 (2014).

14. D. Li, F. Wang, X. Yu, J. Wang, Q. Liu, P. Yang, Y. He, Y. Wang, and M. Zhang, Prog. Org. Coat., 71, 302 (2011).

15. H. Yan, J. Wang, Y. Zhang, and W. Hu, J. Alloys Compd., 678, 171 (2016).

16. J. Tedim, S. K. Poznyak, A. Kuznetsova, D. Raps, T. Hack, M. L. Zheludkevich, and M. G. S. Ferreira, ACS Appl. Mater. Interfaces, 2, 1528 (2010).

17. T. T. X. Hang, T. A. Truc, N. T. Duong, P. G. Vu, and T. Hoang, Appl. Clay Sci., 67-68, 18 (2012).

18. A. Liu, H. Tian, W. Li, W. Wang, X. Gao, P. Han, and R. Ding, Appl. Surf. Sci., 462, 175 (2018)

19. S. A. M. Refaey, S. S. Abd El-Rehim, F. Taha, M. B. Saleh, and R. A. Ahmed, Appl. Surf. Sci., 158, 190 (2000)

20. M. B. Valcarce and M. Vazquez, Electrochim. Acta, 53, 5007 (2008).

21. H. Khani and R. Arefinia, Mater. Corros., 69, 337 (2018).

22. Z. Tang, Curr. Opin. Solid State Mater. Sci., 23, 100759 (2019).

23. S. Takaya, Y. Sudo, T. Yamamoto, and T. Miyagawa, Proc. Japan Concr. Inst., 36, 1270 (2014) [in Japanese].

24. H. Hamasaki, Y. Yamada, T. Fukuyama, and Y. Sudo, Proc. Japan Concr. Inst., 37, 1519 (2015) [in Japanese].

25. J. Xu, Y. Song, Y. Zhao, L. Jiang, Y. Mei, and P. Chen, Appl. Clay Sci., 163, 129 (2018).

26. Y. Su, S. Qiu, D. Yang, S. Liu, H. Zhao, L. Wang, and Q. Xue, J. Hazard. Mater, 391, 122215 (2020).

27. S. Aisawa, S. Takahashi, W. Ogasawara, Y. Umetsu, and E. Narita, J. Solid State Chem., 162, 52 (2001).

28. J. Chen, Y. Song, D. Shan, and E.-H. Han, Corros. Sci., 53, 3281 (2011).

29. F. Prinetto, G. Ghiotti, P. Graffin, and D. Tichit, Microporous Mesoporous Mater, 39, 229 (2000).

30. D. Tichit, O. Lorret, B. Coq, F. Prinetto, and G. Ghiotti, Microporous Mesoporous Mater, 80, 213 (2005).

31. H. Chen, F. Zhang, S. Fu, and X. Duan, Adv. Mater, 18, 3089 (2006).

32. X. Ye, Z. Jiang, L. Li, and Z.-H. Xie, Nanomaterials, 8, 411 (2018).

33. M. A. Iqbal, L. Sun, H. Asghar, and M. Fedel, Coatings, 10, 384 (2020).

34. M. Mizuhata, A. Hosokawa, A. B. Béléké, and S. Deki, Chem. Lett., 38, 972 (2009).

35. A. B. Béléké and M. Mizuhata, J. Power Sources, 195, 7669 (2010).

36. A. B. Béléké, E. Higuchi, H. Inoue, and M. Mizuhata, J. Power Sources, 225, 215 (2013).

37. M. Maki, Y. Mori, Y. Okumura, and M. Mizuhata, Mater. Chem. Phys., 141, 445 (2013).

38. A. B. Béléké, E. Higuchi, H. Inoue, and M. Mizuhata, J. Power Sources, 247, 572 (2014).

39. M. Maki, M. Takigawa, and M. Mizuhata, ACS Appl. Mater. Interfaces, 7, 17188 (2015).

40. M. Takigawa, M. Maki, and M. Mizuhata, Electrochemistry, 83, 803 (2015).

41. H. Maki, M. Inoue, and M. Mizuhata, Electrochim. Acta, 270, 395 (2018).

42. Y. Hoshi, C. Hasegawa, T. Okamoto, M. Soukura, H. Tokieda, I. Shitanda, M. Itagaki, and Y. Kato, Electrochemistry, 87, 78 (2019).

43. H. Zhang, Y. Du, R. Qin, Z. Xu, and Q. Gu, Electrochemistry, 88, 1 (2020).

44. W. Li, A. Fu, Y. Tian, Y. Ju, M. Xue, C. Yin, and Q. Zhang, Electrochemistry, 89, 59 (2021).

45. E. McCafferty, Corros. Sci., 47, 3202 (2005).

46. E. Poorqasemi, O. Abootalebi, M. Peikari, and F. Haqdar, Corros. Sci., 51, 1043 (2009). 